\title{
What is the research base for the use of dietary supplements?
}

\author{
Malden C Nesheim* \\ Cornell University, Ithaca, New York, USA \\ Submitted 2 August 1998: Accepted 15 October 1998
}

\begin{abstract}
The market for dietary supplements in the USA was estimated as about 11.8 billion dollars in 1997 with a growth rate of 10-14\% projected in the next 3 years. Data from the Food and Drug Administration collected in 1995 indicate that over $55 \%$ of adults surveyed used some type of dietary supplement. The marketing of dietary supplements in the USA has been essentially deregulated by the passage of the Dietary Supplement Health and Education Act of 1994 (DSHEA). This legislation defined dietary supplements, made manufacturers responsible for the safety of supplements and allowed certain statements of nutrition support to be made on supplement labels. The US Congress in passing the DSHEA indicated that supplements should be available on the market so that consumers could make decisions about their use for themselves and their families. Unfortunately, information about the research base for supplement claims is not readily accessible to health professionals and consumers. There is a need for authoritative reviews of the data underlying supplement claims to assist public health professionals in their role of providing advice to the public about dietary supplements.
\end{abstract}

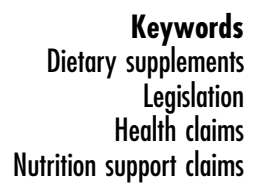

Dietary supplements have become the hottest item in the nutrition-related marketplace. According to industry data ${ }^{1}$, the market for dietary supplements in the USA in 1997 was valued at 11.8 billion dollars, and has grown $12-16 \%$ in the past 3 years. Industry projections indicate an expected sales growth of $10-14 \%$ in the next 3 years ${ }^{1}$. Vitamins and minerals made up the major part of the market, with $51 \%$ of the sales, but sales of herbal products/botanicals amounted to 33\% of the market in 1997 and represent the fastest growing segment ${ }^{1}$.

Data collected by the Food and Drug Administration (FDA) in 1995 indicated that $55 \%$ of the adults surveyed used some type of dietary supplement ${ }^{2}$. Given the growth of the market, the FDA survey probably underestimates the number of users today. Though there are many contributing factors to the growth of the market, the marketing of supplements has been greatly facilitated by the passage of the Dietary Supplement Health and Education Act of 1994 (DSHEA) ${ }^{3}$. This legislation has had a major impact on the supplement industry because it has delineated the role of the FDA in regulating these products and has essentially deregulated the industry.

Dietary supplements are defined in the DSHEA ${ }^{3}$ as a product (other than tobacco) intended to supplement the diet that bears or contains one or more of the following dietary ingredients: (a) a vitamin; (b) a mineral; (c) a herb or other botanical; (d) an amino acid; (e) a dietary supplement used by man to supplement the diet by increasing the total dietary intake; or (f) a concentrate, metabolite, constituent, extract or combination of any ingredient described in (a-e). The law provides that a dietary supplement is a product that is labelled as a dietary supplement and is not represented for use as a conventional food or as a sole item of a meal or the diet. These products can be ingested as a capsule, powder, gelcap, tablet, liquid or other form. The DSHEA specifically excludes dietary supplements from regulation as food additives. As one can see, this definition is highly inclusive and contains many components nutritionists would not normally consider to have nutritional functions.

The DSHEA makes manufacturers responsible for the safety of products marketed. There is no pre-marketing safety determination by the FDA and the burden of proof is on the FDA to show that a product is not safe. There is provision in the law that the Secretary of the HHS can declare a product an imminent hazard and remove it from sale.

DSHEA allows manufacturers to make certain nutrition support statements on labels also without FDA approval. As specified in the legislation, these claims may be made if

the statement claims a benefit related to a classical nutrient deficiency disease and discloses the prevalence of such disease in the United States, describes the role of a nutrient or dietary ingredient intended to affect the structure or function in 
humans, characterizes the documented mechanism by which a nutrient or dietary ingredient acts to maintain such structure or function, or describes general well-being from consumption of a nutrient or dietary ingredient.'

The FDA must be notified within 30 days when a product is marketed with a nutrition support statement but the FDA does not approve such claims.

The label must carry the disclaimer 'This statement has not been evaluated by the Food and Drug Administration. This product is not intended to diagnose, treat, cure, or prevent any disease.' The manufacturer is required to have substantiation that the claim is truthful and not misleading but the 'substantiation file' is not made public unless some enforcement action may be taken in court.

The statements of nutrition support are not health claims of the type defined by the Nutrition Education and Labeling Act of $1990^{4}$ as a statement that characterizes a relationship between a nutrient or food component and a specific disease- or healthrelated condition. In contrast to nutrition support claims, health claims require prior FDA approval based on a determination that there is significant scientific agreement that the claim is valid. Nutrition support statements may not claim to diagnose, treat, cure or prevent any disease.

There are several other important provisions of the DSHEA, including the exemption of certain literature from being classified as labelling, the provision of special labelling requirements for supplements and the establishment of an Office of Dietary Supplements at the National Institutes of Health. The DSHEA also directed the President to appoint a Commission on Dietary Supplement Labels to consider aspects of the DSHEA that might need further consideration. After 18 months of public hearings and meetings, the Commission reported to the President, the Congress and the Secretary of HHS its findings on 24 November $1997^{5}$. The report is accessible on the Internet at http://web.health.gov/dietsupp and can be requested from the Government Printing Office, Superintendent of Documents (PO Box 371954, Pittsburgh, PA 152507954, USA; 202-512-1800).

The passage of the DSHEA was the culmination of a long history of attempts by the FDA to regulate the potency and standards of efficacy for vitamin and mineral preparations and to regulate the use of botanical products and other substances primarily as drugs. These attempts at regulation were often overturned by congressional action that prevented restrictive rules from being implemented. This regulatory history has been outlined in the Commission Report ${ }^{5}$ and the evolution of the final form of the DSHEA has been described in detail by Bass and Young ${ }^{6}$.
Congressional action seemed to be in response to pressures generated by a coalition of the supplement industry and committed supplement consumers. The Congress has been reported to have received more mail on the subject of dietary supplement legislation than any other matter that has come before the Congress including the Vietnam war!

Consumer choice is one of the themes that comes through in examining the legislative history in the regulation of dietary supplements. In establishing the Commission on Dietary supplement labels, the DSHEA indicated that the Commission was to 'evaluate how best to provide truthful, scientifically valid, and not misleading information to consumers so that such consumers may make informed and appropriate health care choices for themselves and their families'3. The Report of the Commission ${ }^{5}$ emphasized that consumers should know the nature of the evidence supporting a statement of nutrition support associated with a product. Is the statement based on substantial laboratory and clinical evidence or is the claim based on a long history of use in a traditional medicine? The report urges manufacturers to make publicly available balanced and not misleading summaries of the evidence substantiating statements of nutrition support and product safety.

Provisions of the DSHEA that exempted certain publications from being considered labelling were in response to FDA rulings that a company's distribution of certain peer reviewed scientific publications indicated that some dietary supplements were drugs (see Bass and Young ${ }^{6}$ ). The DSHEA has a provision that indicates that a publication, including an article, a chapter of a book or an official abstract of a peer reviewed scientific publication that appears in an article and was prepared by the author or the editors of the publication, which is reprinted in its entirety, shall not be defined as labelling when used in connection with the sale of a dietary supplement to consumers. The provision applies if publication is not false or misleading; does not promote a particular manufacturer or brand of a dietary supplement; is displayed with other items on the same subject to present a balanced view of the evidence; is physically separate from the dietary supplement; and does not have any information appended to it. This provision means that a publication that meets these standards may refer to research where a supplement was used to treat or prevent a specific disease even though the claim cannot be made on label material for the product.

Although this provision of the DSHEA was supposed to ensure that consumers had access to scientific information about supplements so that they could make appropriate decisions about their use, the provision is likely to be more helpful to the seller than to the buyer of supplements. There is no standard for what is an appropriate 'peer reviewed publication' and individual 
papers do not constitute a comprehensive review of the work that has been done. Given that the definition of dietary supplements is so inclusive, nutritionists and dietitians are likely to be asked about their assessment of the value of supplements ranging from the traditional vitamin and mineral supplements to the herbal products and metabolites. There is an urgent need to have unbiased, peer reviewed comprehensive evaluations available to the public health nutrition community that assess the scientific evidence as to the effectiveness and safety of individual dietary supplements.

In 1995, the largest selling botanical supplement in the US was Echinacia ${ }^{5}$. The products sold are primarily made from extracts of the common purple cone flower, Echinacea purpurea. The purple cone flower is native to the USA and was widely used for medicinal purposes by the great plains Indians. An Echinacea supplement is generally sold with a nutrition support statement indicating that it supports a healthy immune system. Echinacea extracts are taken as supplements by most users as a preventive or modulator of colds and flu.

A Medline ${ }^{7}$ key word search produced 48 publications dealing with Echinacea since 1965 in the medical literature indexed by this data base. There are few clinical studies with human subjects among the publications identified. It is clear, however, that much of the literature associated with this botanical preparation is not published in 'main line' journals that are covered by Medline. Papers by Melchart et al. in $1994^{8}$ and Parnham published in $1996^{9}$ have reviewed the clinical studies that have been done with Echinacea. The paper by Parnham ${ }^{8}$ is claimed by the author to be the first assessment of the clinical evidence of the efficacy of Echinacea published in English. Most of the results reviewed were published in Germany and some of the studies were unpublished and obtained from private data bases. Both authors concluded that although the quality of many of the study designs was low, and that many questions remained as to the type of preparations that might be effective and at what dose, there was evidence of immunomodulation by Echinacea extracts.

The science base for other botanical supplement claims is somewhat more accessible. A Medline ${ }^{7}$ search for citations for Saw Palmetto (Serenoa repens) finds some 28 papers cited since 1967, among which are several human clinical trials dealing with treatment of benign prostate hyperplagia. Several papers also deal with potential mechanisms for the effectiveness of the product. Several reviews are also available but are published in journals seldom read by nutrition professionals. Many of these papers were published in Europe in languages other than English.

A case can be made for the same lack of an accessible base of clinical data as to efficacy of many other compounds or mixtures of products that are marketed as dietary supplements. Amino acids, metabolites and hormones are all marketed as dietary supplements with statements of nutrition support.

In addition to the marketing opportunities provided by the provisions of the DSHEA, dietary supplement use is likely to increase because of new advice to the public by traditional sources of nutrition recommendations. The recommended dietary allowances published by the Food and Nutrition Board of the Institute of Medicine ${ }^{10}$ have up to now advised the public that adequate levels of nutrients for healthy individuals could be obtained by consumption of a varied diet. Similar advice is provided by the 1995 Dietary Guidelines for Americans ${ }^{11}$ issued by the US Departments of Agriculture and Health and Human Services. Recently, however, new recommendations encourage supplement use under some circumstances. The Food and Nutrition Board has published new values for dietary reference intakes for several vitamin and mineral nutrients ${ }^{12,13}$.

To meet the recommended level of calcium intake by older adults (over 50 years of age) of $1200 \mathrm{mg} \mathrm{day}^{-1}$, it is likely that most individuals would need to take a calcium supplement or use calcium fortified foods. Similarly, for vitamin D, the recommendation for adequate intake for older adults has been raised and a supplement may be needed to reach the level set by the committee. The recommendations for folate advise women capable of becoming pregnant to consume $400 \mu \mathrm{g} \mathrm{day}^{-1}$ as a supplement or from fortified foods in addition to the folate consumed from a varied diet. Individuals over 50 years of age are advised to meet their recommended daily allowance for vitamin $\mathrm{B}_{12}$ by using foods fortified with the vitamin or by a supplement. This advice represents a major departure from the recommendations and philosophy of earlier editions of the recommended dietary allowances ${ }^{10}$. The recommendations probably mean that consumption of a multi-vitamin and mineral supplement will be recommended for most Americans. Though the new publications give the rationale for these recommendations, some complete in-depth reviews of the data used to underpin these recommendations would be helpful to the nutrition community.

As a result of these considerations Public Health Nutrition is inviting the submission of reviews that can provide an in-depth understanding of the research base underlying the use of dietary supplements. These reviews should be useful to the nutrition community and hopefully provide a better basis for informing the public about the science underlying dietary supplement claims and recommendations. Perhaps in this way, individuals can make an informed choice as to the use of dietary supplements for themselves and their families as envisioned by the US Congress when the DSHEA was enacted. 


\section{References}

1 Anonymous. Nutrition industry builds momentum. Nutri. Business J. 1997: 2: 1-5.

2 Roe BE, Derby BM, Levy AS. Demographic, lifestyle, and information use characteristics of dietary supplement user segments. 1997. Unpublished study cited in report of the Commission on Dietary Supplement Labels. Department of Health and Human Services, Washington DC.

3 Dietary Supplement Health and Education Act of 1994. 108 Stat. 4325. Public Law 103-417, United States Congress.

4 The Nutrition Education and Labeling Act of 1990, 104 Stat. 2353. Public Law 101-535, United States Congress.

5 Report of the Commission on Dietary Supplement Labels. Department of Health and Human Services, Washington DC, 1997.

6 Bass IS, Young AL. Dietary Supplement Health and Education Act; a legislative bistory and analysis. The Food and Drug Law Institute, Washington DC, 1996.

7 Medline, National Library of Medicine. US Department of Health and Human Services, Bethesda, MD.

8 Melchart $\mathrm{D}$, Linde $\mathrm{K}$, Worku $\mathrm{F}$, Bauer $\mathrm{R}$, Wagner $\mathrm{H}$.
Immunomodulation with Echinacea - a systematic review of controlled clinical trials. Phytomedicine 1994; 1: 245-54.

9 Parnham MJ. Benefit-risk assessment of the squeezed sap of the purple coneflower (Echinacea purpurea) for long term oral immunostimulation. Phytomedicine 1996; 3: 95-102.

10 Recommended Dietary Allowances, tenth edition. National Research Council National Academy of Sciences, Washington, DC, 1989.

11 USDA and HHS 1995 Dietary Guidelines for Americans, fourth edition. Home and Garden Bulletin 232: USDA, Washington DC.

12 Food and Nutrition Board 1997. Dietary Reference Intakes calcium, phosphorus, magnesium, vitamin D and fluoride. Standing Committee on the Scientific Evaluation of Dietary Reference Intakes. Institute of Medicine, National Academy Press, Washington DC.

13 Food and Nutrition Board 1998. Dietary Reference Intakes: thiamin, riboflavin, niacin, vitamin $B_{6}$, folate, vitamin $B_{12}$, pantothenic acid, biotin, and choline. Standing Committee on the Scientific Evaluation of Dietary Reference Intakes. Institute of Medicine, National Academy Press, Washington DC. 